\title{
Proposta do Uso de Múltiplos Recursos para o Ensino de Pensamento Computacional no Ensino Fundamental II: Um Relato de Experiência
}

\author{
Oto B. Assunção ${ }^{1}$, Nathalia C. Braga ${ }^{1}$, Raquel O. Prates ${ }^{1}$, Elaine S. França ${ }^{2}$ \\ ${ }^{1}$ Departamento de Ciência da Computação \\ Universidade Federal de Minas Gerais (UFMG) - Belo Horizonte, MG - Brazil \\ ${ }^{2}$ Centro Pedagógico da Escola de Educação Básica e Profissional da UFMG \\ \{oto.braz, nathalia.campos, rprates\}@dcc.ufmg.br, lainesf@ufmg.br
}

\begin{abstract}
Computational Thinking (CT) competencies are essential nowadays. There are many tools and activities that educators can utilize to promote the development of such abilities. This work reports an experience of teaching $C T$ to 16 th grade students. According to the students' perceptions, the experience was positive, and the tools and activities were fun and easy for them to use and understand.
\end{abstract}

Resumo. As competências do Pensamento Computacional (PC) são essenciais nos dias de hoje. Existem diversas ferramentas e atividades que educadores podem usar para estimular o desenvolvimento destas habilidades. Este trabalho relata uma experiência de ensino do PC para 16 alunos do $6^{\circ}$ ano do Ensino Fundamental. Segundo a percepção dos alunos, a experiência foi positiva e as ferramentas e atividades foram divertidas e fáceis de serem feitas e entendidas.

\section{Introdução}

O Pensamento Computacional (PC), termo cunhado por Jeannette Wing [Wing 2006], se refere a um conjunto de competências para formulação, análise e solução de problemas do mundo real. Wing argumenta que tais habilidades são fundamentais para a sociedade contemporânea, sendo tão importantes quanto saber ler e escrever.

Diversos países como Austrália, Estados Unidos e Coreia do Sul já integraram ou vêm fazendo a integração do ensino de PC na educação básica [Heintz et al. 2016]. No Brasil, a importância que a computação tem e terá para a sociedade é reconhecida por diversos profissionais e instituições educacionais [SBC 2017, SBC 2019, MEC 2018]. Apesar de várias iniciativas e pesquisa estarem sendo nacionalmente [Santos et al. 2018], o Brasil ainda está atrasado em relação aos países do Primeiro Mundo.

São diversas as abordagens que educadores utilizam para ensinar PC a alunos. No trabalho de [Carlos et al. 2018] são utilizadas diversas ferramentas para o ensino. Uma abordagem comumente utilizada é a mesclagem entre abordagens desplugadas e plugadas [Braga et al. 2018]. Há também trabalhos focados em apenas uma única abordagem ou ferramenta para o ensino [Neto et al. 2018, Duarte et al. 2017].

Este artigo relata os resultados da primeira etapa de um trabalho de mestrado cujo o objetivo é propor uma metodologia para introduzir o PC à alunos do Ensino Fundamental II. Um curso para estimular o desenvolvimento e utilização de habilidades do PC 
VIII Congresso Brasileiro de Informática na Educação (CBIE 2019)

Anais do XXV Workshop de Informática na Escola (WIE 2019)

através do pensamento algorítmico foi conduzido com 16 alunos do $6^{\circ}$ ano. Durante o curso, diversos dados foram coletados para avaliarmos, sob a perspectiva dos alunos, a experiência e as ferramentas e atividades utilizadas.

\section{Metodologia}

Uma pesquisa-ação foi conduzida no Centro Pedagógico da Escola de Educação Básica e Profissional da UFMG. Ela foi conduzida através de um Grupo de Trabalho Diferenciado (GTD) de PC. A cada semestre, GTDs de diferentes temas são oferecidos na escola e os alunos escolhem em quais eles gostariam de participar. O GTD de PC foi conduzido pelos autores deste trabalho e teve 14 encontros de 1 h20min cada. Participaram 16 (8 meninos e 8 meninas) alunos do sexto ano do Ensino Fundamental II. Todos eles já tinham utilizado o computador antes de iniciar o curso.

Diversas ferramentas e materiais foram utilizados no GTD PC, todas elas disponíveis gratuitamente. A escolha de quais, quando e como eles seriam utilizados foi baseada em uma ferramenta epistêmica chamada Metáforas de Perspectivas Culturais (MPC) [de Castro Salgado et al. 2011]. As MPC serviram de apoio para considerarmos a complexidade dos conceitos e das ferramentas a fim de que eles fossem apresentados em ordem gradual de dificuldade. A Tabela 1 apresenta a relação entre as aulas, ferramentas e conceitos explorados. A descrição detalhada das ferramentas e atividades conduzidas estão disponíveis online ${ }^{12}$.

Tabela 1. Relação de aulas, ferramentas, conteúdos e atividades

\begin{tabular}{l|l|l} 
Aulas & Materiais e Ferramentas & Conteúdo / Atividades \\
\hline Aula 1 & Estacionamento Algorítmico & Raciocínio Lógico (desplugada) \\
Aula 2 & Programação em Papel & Algoritmos (desplugada) \\
Aula 3 & Kahoot!, LightBot & Algoritmos \\
Aula 4 & Kahoot!, Code.org & Algoritmos, Programação em Blocos \\
Aula 5 & Kahoot!, Code.org & Estruturas de Repetição \\
Aula 6 & Code.org & Análise e correção de problemas \\
Aula 7 & Code.org & Condicionais \\
Aula 8 & Kahoot!, Scratch & Revisão geral e introdução ao Scratch \\
Aula 9 & Scratch & Anime um Nome \\
Aula 10 & Scratch & Criação de jogos ou histórias \\
Aula 11 & Scratch & Bugs no Ciclo da Água \\
Aula 12 & Scratch & Alteração de um jogo \\
Aula 13 & Scratch & Alteração de um jogo \\
Aula Final & Kahoot, Scratch & Revisão sobre o Scratch. Alunos jogaram os jogos uns dos \\
& & outros \\
\hline
\end{tabular}

Durante o decorrer do GTD, foram coletados quatro tipos dados: (i) dados sobre o perfil e experiência dos alunos com a tecnologia através de um questionário eletrônico, (ii) pontos de interesse (e.g., reações dos alunos durante as atividades) através da observação dos pesquisadores e gravações de vídeo, (iii) avaliação das atividades através de questionários em papel ${ }^{3}$ aplicados ao fim de cada aula e (iv) dados mais qualitativos sobre a experiência através de grupos focais.

\section{Resultados}

Nesta seção são discutidos os principais resultados do GTD de PC, considerando os questionários de avaliação das atividades, a observação dos pesquisadores e grupos focais.

\footnotetext{
${ }^{1}$ Descrição das aulas: http: / / tiny . cc/atividades

${ }^{2}$ Descrição das ferramentas: http: / / tiny . cc/ferramentas

${ }^{3}$ Questionário de avaliação das atividades: http://tiny.cc/avaliando_atividades
} 
VIII Congresso Brasileiro de Informática na Educação (CBIE 2019)

Anais do XXV Workshop de Informática na Escola (WIE 2019)

\subsection{Avaliação das Ferramentas e Atividades}

Foram avaliadas a aceitabilidade e dificuldade das ferramentas e atividades conduzidas no GTD. O Estacionamento Algorítmico e LightBot foram utilizados em apenas uma aula. Por outro lado, o Code.org e o Scratch foram utilizados em múltiplas aulas, então apresentamos o resultado consolidado de todos os questionários aplicados para cada um deles. A atividade Programação em Papel não pôde ser avaliada devido à falta de tempo.

A aceitabilidade foi verificada a partir do primeiro item do questionário de avaliação, o qual perguntava o quanto os alunos gostaram da atividade em questão. Os resultados são apresentados na Figura 1:

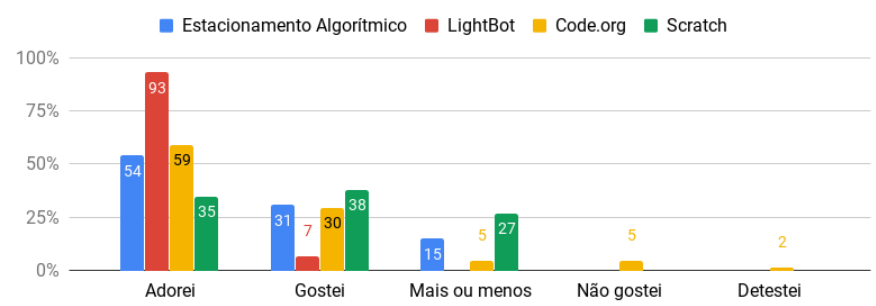

Figura 1. Aceitabilidade das ferramentas e atividades

Em geral, os resultados foram positivos para todas as quatro ferramentas avaliadas. Apenas o Code.org foi avaliado negativamente pelos alunos (2\% marcaram que detestaram e 5\% que não gostaram). Alguns alunos comentaram nos grupos focais que o Code.org era entediante e repetitivo. Vale ressaltar que o Code.org foi usado em 4 aulas, e embora as lições fossem diferentes, as atividades contidas nelas eram bem parecidas. $\mathrm{O}$ LightBot foi a ferramenta que os alunos mais gostaram (88\% marcaram que adoraram e $6 \%$ que gostaram). De fato, foi percebido durante as aulas e pelos comentários escritos nos questionários de avaliação que os alunos queriam jogar mais o LightBot.

O grau de dificuldade das atividades conduzidas para os alunos do $6^{\circ}$ ano foi avaliado para que ajustes pudessem ser realizados em edições futuras do curso. Os resultados estão sumarizados na Figura 2. Os alunos em geral não acharam as atividades difíceis, mesmo que não as achassem sempre fáceis. Nenhum aluno considerou que o Estacionamento Algorítmico foi uma atividade difícil. Além disso, apenas uma pequena parte deles achou que o LightBot, Code.org e Scratch foram difíceis (7\%, 8\%, 5\% respectivamente).

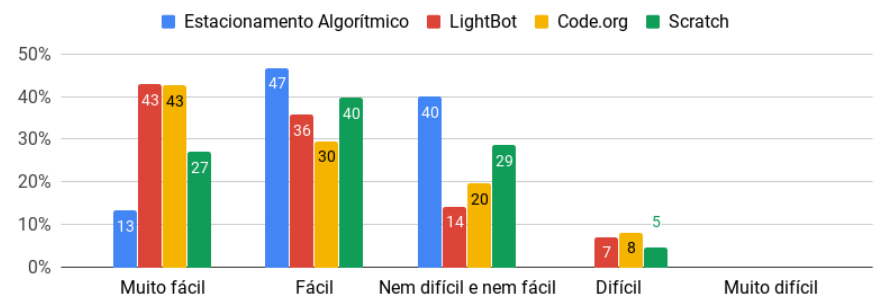

Figura 2. Dificuldade das ferramentas e atividades

\subsection{Resultado Consolidado}

O resultado agregado de todos os questionários respondidos ao decorrer do GTD foi utilizado para avaliarmos a experiência segundo a percepção dos alunos. As Figuras 3 e 4 
VIII Congresso Brasileiro de Informática na Educação (CBIE 2019)

Anais do XXV Workshop de Informática na Escola (WIE 2019)

apresentam o grau de satisfação dos alunos (i.e., aceitabilidade agregada) e a dificuldade do GTD, respectivamente.

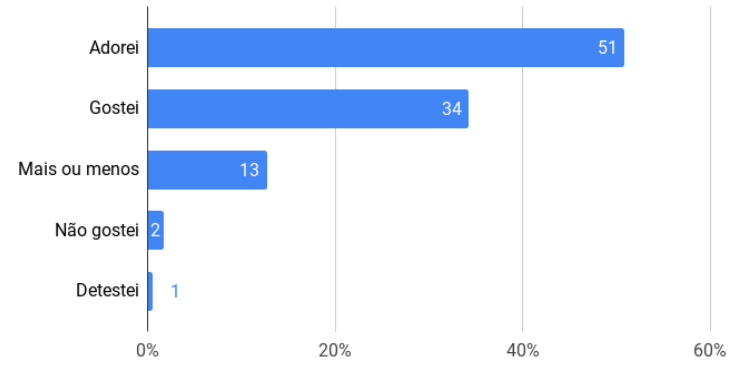

Figura 3. Grau de Satisfação

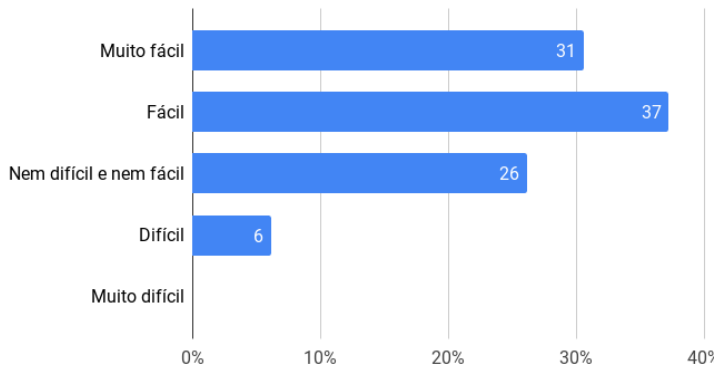

Figura 4. Dificuldade do GTD

Os resultados sobre a satisfação em relação às atividades do GTD foram extremamente positivos. Apenas 3\% das respostas foram negativas e $85 \%$ delas foram positivas. Dentre as respostas positivas, $34 \%$ foram para o item "Gostei" e $51 \%$ para o item "Adorei". Em 13\% das respostas, as atividades não foram consideradas nem ruins e nem boas.

Em geral (em 68\% das avaliações) os alunos acharam que as atividades do GTD foram no mínimo fáceis (fáceis em $37 \%$ das respostas e muito fáceis em 31\%). Em 26\% das avaliações, as atividades foram consideradas 'nem difíceis nem fáceis' e apenas em $6 \%$ das respostas, eles disseram que a atividade foi difícil.

\subsection{O Kahoot! como Ferramenta de Revisão e Avaliação}

O Kahoot! foi usado para rever conceitos e atividades vistas em aulas anteriores. Desde o início, os alunos ficaram empolgados com uso do Kahoot! e sempre pediam para continuarmos a utilizá-lo no GTD. Pôde se notar claramente que eles estavam adorando a experiência e a atmosfera competitiva.

Avaliamos o Kahoot! através do questionário que a própria plataforma disponibiliza aos usuários ao fim da atividade. É perguntado o quanto o usuário se divertiu, o quanto aprendeu, se ele recomendaria o Kahoot e como ele sentiu no fim da experiência. Os resultados dos questionários foram positivos e podem ser acessados online ${ }^{4}$.

O Kahoot! foi mencionado por todos os alunos nos grupos focais quando questionados sobre as ferramentas que eles gostaram mais. Eles o consideraram bastante divertido e, ao mesmo tempo, útil para o aprendizado. Após cada pergunta ter sido respondida pelos os alunos, o conteúdo da pergunta e as alternativas eram discutidos com todos e explicações sobre o por quê de algo estar certo ou errado eram dadas.

O Kahoot! é uma ferramenta com grande potencial de ser utilizada não somente para revisão de conteúdos, mas também para a condução de stealth assessments por educadores, ou seja, avaliar alunos sem que eles saibam que estão sendo avaliados.

\section{Conclusão}

O pensamento computacional e suas habilidades podem ser praticadas e exploradas de diversas formas. Nesta pesquisa-ação, utilizamos múltiplas ferramentas para facilitar a

\footnotetext{
${ }^{4}$ http://tiny.cc/resultados-kahoots
} 
VIII Congresso Brasileiro de Informática na Educação (CBIE 2019)

Anais do XXV Workshop de Informática na Escola (WIE 2019)

apresentação e prática de diferentes conceitos com níveis de complexidade diversos. A experiência foi vista como positiva e divertida pelos alunos. Foram notados pontos positivos e negativos ao utilizar diferentes ferramentas para condução das atividades.

O uso de múltiplas ferramentas auxiliou na manutenção da motivação e foco dos alunos ao decorrer do curso. A realização de atividades similares que utilizam uma mesma ferramenta pode se tornar cansativa e entediante para crianças (como foi o caso do Code.org). Esta abordagem pode não ser eficiente quando número de aulas disponíveis para ensinar os conteúdos é pequeno. Apesar de haver uma exposição gradativa a temas mais complexos, a transição entre ferramentas pode demandar mais tempo uma vez que existe uma curva de aprendizado das ferramentas. Assim, o planejamento das aulas deve ser bem feito para que tal metodologia possa ser utilizada eficientemente.

Os próximos passos desta pesquisa incluem: (i) a análise aprofundada dos grupos focais, (ii) condução de novos GTDs, sendo um deles, a continuação do GTD relatado neste artigo, e o outro, um realizado do começo com outros alunos e, por fim, (iii) a consolidação da metodologia e recomendações para educadores.

\section{Agradecimentos}

O autor Oto Braz Assunção agradece ao CNPq pelo financiamento parcial deste trabalho.

\section{Referências}

Braga, L. V. et al. (2018). Programchildren: Levando tecnologia para crianças de uma escola pública. In XXIV WIE, page 295.

Carlos, L. et al. (2018). Um relato de experiência da escola de verão de programação para crianças. In XXIV WIE, page 41.

de Castro Salgado, L. C. et al. (2011). On the epistemic nature of cultural viewpoint metaphors. In XIHC \& V CLIHC, pages 23-32.

Duarte, K. et al. (2017). Abordagem para o ensino da lógica de programação em escolas do ensino fundamental ii através da ferramenta scratch 2.0. In XXIII WIE, page 175.

Heintz, F. et al. (2016). A review of models for introducing computational thinking, computer science and computing in k-12 education. In FIE.

MEC (2018). Base nacional comum curricular. Ministério da Educação. Acessado em: 17-07-2019.

Neto, M. et al. (2018). Robótica educacional uma ferramenta para ensino de lógica de programação no ensino fundamental. In XXIV WIE, page 315.

Santos, P. C. et al. (2018). A mapping study of computational thinking and programming in brazilian k-12 education. In 2018 FIE, pages 1-8.

SBC (2017). Referenciais de formação em computação: Educação básica. Acessado em: 14-07-2019.

SBC (2019). Diretrizes para ensino de computação na educação básica. Acessado em: 15-07-2019.

Wing, J. (2006). Computational thinking. Communications of the ACM, pages 33-35. 